\title{
O PENSAMENTO EDUCACIONAL EM MARX E GRAMSCI E A CONCEPÇÃO DE POLITECNIA
}

\author{
THE EDUCATIONAL THINKING IN MARX AND GRAMSCI AND THE POLYTECHNIC CONCEPTION
}

\author{
Celso João Ferretti ${ }^{1}$
}

Resumo É desejável e necessário compreender historicamente a origem da concepção de politecnia associada à formação integrada, assim como da própria formação integrada, dois termos cuja polissemia pode conduzir a interpretações diversas e mesmo antagônicas. Tanto a concepção de politecnia quanto de formação integral aparecem na literatura ligadas à formação escolar, ainda que não se refiram exclusivamente a ela. O objetivo deste texto é duplo. Pretende, de um lado, situar ambas as concepções no universo teórico do materialismo histórico, ressalvando que, por não serem exclusivas deste universo, comparecem em outros, com diferentes significados. De outro lado, intenciona examinar, com algum detalhe, de que forma dois autores-chave - Marx e Gramsci - elaboram suas visões sobre as relações entre a educação e o trabalho mediadas pela concepção da politecnia e da formação integral e, de forma bastante breve, quais as aproximações e distanciamentos entre eles, relativamente a tal questão.

Palavras-chave relação trabalho-educação; politecnia; omnilateralidade.
Abstract It is desirable and necessary to historically understand the origin of the polytechnic conception associated to the integrated education, as well as the very own integrated education, two terms whose polysemy may lead to different and even opposing interpretations. Both the polytechnic and the integral education conceptions can be found in literature connected to the school education, even if not exclusively referring to it. The purpose of this paper is twofold. On the one hand, it is intended to place both conceptions within the theoretical universe of the historical materialism, being pointed out that, as they are not exclusive from this universe, they can be found in other universes, with different meanings. On the other hand, it is intended to examine, in details, how two key authors - Marx and Gramsci - develop their views regarding the relationships between education and work mediated by the polytechnic conception and the integral education, and, in a very summarized manner, which are the similarities and differences between then, in regards to this issue.

Keywords work-education relationship; polytechnic; one-sidedness 


\section{Gênese, desenvolvimento e contradições da escola no capitalismo}

Conforme Saviani (1994), o termo escola significa, em grego, lugar do ócio, ocupado, na antiguidade grega, por componentes das classes ociosas que, por não necessitarem do trabalho para sobreviver, podiam dedicar-se a atividades que lhes permitiam educar-se, isto é, obter seu enriquecimento cultural. Em outra situação estava grande parte da população, cuja educação se fazia no próprio processo de trabalho, não havendo, portanto, nem a demanda, nem a necessidade de escolas a ela destinada. Tal situação persistiu, segundo o mesmo autor, na Idade Média, com a diferença de que, ao termo ócio, acrescenta-se a expressão 'com dignidade', significando que o tempo ocioso dos que não viviam do trabalho deveria ser ocupado com 'atividades consideradas nobres', entendidas estas como as ligadas à guerra e à vida aristocrática. A educação dessa parcela da sociedade dava-se, de acordo com Saviani, em escolas paroquiais, escolas catedralícias e escolas monacais. Lembra o autor que, na economia feudal, a parcela da população que deveria trabalhar para sobreviver dedicava-se às atividades rurais, das quais fazia parte o artesanato. O desenvolvimento desse último criou as condições para atividades mercantis que se deslocaram para as cidades, ou burgos, nas quais passaram a proliferar as trocas entre produtores, organizadas sob a forma de feiras. O comércio assim desenvolvido criou as condições para a acumulação primitiva que estimulou "o deslocamento do eixo do processo produtivo do campo para a cidade, da agricultura para a indústria" (Saviani, 1994, p. 154).

Consequências decorrem desse processo. A mais importante, evidentemente, é a constituição da sociedade moderna fundada na substituição do direito natural pelo direito positivo e, por extensão, na noção de liberdade, ou seja, na ideologia do liberalismo. Para Saviani (1994, p. 155), “a noção de liberdade, como princípio do modo de organização da sociedade moderna, (...) significa que cada um é livre para dispor de sua propriedade". As "propriedades' diferem segundo a condição social dos proprietários. Entre as propriedades dos setores que historicamente vinham acumulando bens a partir das trocas mercantis, estão as dos meios de produzir industrialmente. A propriedade dos antigos servos passou a ser, tendo perdido as terras que cultivavam, sua força de trabalho. Como homens livres, mas desprovidos de seus meios de subsistência, poderiam, para sobreviver, vender sua força de trabalho.

A constituição da sociedade moderna, assentada sobre a produção industrial e sobre a urbanização implicou a necessidade de generalizar o acesso à escola por duas razões principais. Em primeiro lugar, pela demanda por conhecimentos por parte da produção industrial nascente. Em segundo, pela natureza da sociedade fundada no direito positivo, que passa a exigir a 
generalização do domínio da leitura e da escrita. Nesse sentido, o próprio desenvolvimento histórico da sociedade urbano-industrial passou a exigir a expansão da educação escolar, não apenas em função do processo produtivo, mas também como resposta às demandas relativas ao desenvolvimento de hábitos necessários à vida nas cidades ou, em termos políticos, à formação do cidadão.

Tal centralidade atribuída à educação escolar promoveu o ofuscamento de outras formas de educação então em vigor (a realizada pela igreja e pela família, por exemplo), mas não seu desaparecimento. Esse papel central permanece na atualidade, mas observa-se, ao mesmo tempo, a tendência de sua secundarização, especialmente depois que se generalizaram outras formas de educação e outras agências, que não a escola, voltadas para a promoção de atividades de caráter educativo como, por exemplo, "sindicatos, partidos, associações dos mais diversos tipos (...) clubes de mães" (Saviani, 1994, p. 158) e, cada vez mais, as ONGs. A disseminação de microcomputadores e a relativa facilidade de acesso à informação por via eletrônica, a multiplicidade de outros meios pelos quais é possível obtê-la (revistas, televisão) tendem a fazer crer que a educação escolar (neste caso, confundida com a disseminação da informação) é apenas uma dentre várias outras formas de educar; ainda que várias delas, às quais deve-se acrescentar a educação a distância, se estruturem sob a 'forma escolar', como salienta Vincent (2001).

Saviani considera que tal situação explicita, contraditoriamente, tanto a valorização quanto a desvalorização da educação escolar. Parece-me que, no plano nacional, hoje, essa contradição se faz cada vez mais patente. Com efeito, após as reformas da década de 1990, multiplicam-se os discursos que reafirmam com insistência a contribuição da escola para o desenvolvimento do país e para a empregabilidade de trabalhadores excluídos de postos de trabalho formais em diferentes ramos produtivos, assim como nos setores de serviços e agrícola e, simultaneamente, observa-se, na mesma proporção, a queda da qualidade da educação regular oferecida, assim como a valorização de formas compensatórias e alternativas de educação, especialmente para os setores populares.

Essa constatação remete à segunda contradição apontada por Saviani, qual seja, a que se refere à forma como o embate de classes penetra o campo educacional. Tal contradição se expressa, nos séculos XVIII e XIX, por meio do posicionamento diverso assumido por teóricos da economia política clássica em relação à educação dos trabalhadores (adultos ou não). O ponto de vista assumido por alguns desses teóricos era o de que a escola seria pouco desejável para os trabalhadores e seus filhos, pois representaria tempo subtraído à produção. Tal ponto de vista foi objeto da crítica de Engels quando discutiu $A$ situação da classe trabalhadora na Inglaterra. Nesse texto o autor evidencia não só a pouca disponibilidade das crianças para a frequência 
diurna às poucas escolas existentes, devido às suas atividades laborais na fábrica, como também às condições adversas daquelas que se dispunham a frequentar as aulas no período noturno, ou nas escolas de domingo, dado o cansaço resultante do trabalho exaustivo que realizavam por períodos de dez horas ou mais. Nogueira (1990) acrescenta, com base em Engels, que, além disso, as escolas destinadas aos filhos dos trabalhadores, além de serem mal instaladas fisicamente, ficavam sob a responsabilidade de operários aposentados ou desempregados que não reuniam condições de promover qualquer tipo de aprendizagem significativa.

Todavia, de acordo com Saviani, teóricos como Adam Smith, embora também do âmbito da economia clássica, viam na educação básica dos trabalhadores, e apenas nela, contribuições positivas para a acumulação capitalista, pois esta os tornaria mais capazes de viver na sociedade moderna e de se tornarem mais produtivos. Ultrapassado esse nível, a educação poderia voltar-se contra os interesses do capital, pois o saber adquirido converteria os trabalhadores em proprietários de um dos meios de produção (o conhecimento de base científica). O ponto de vista de Smith prevaleceu, contribuindo para demarcar o papel contraditório reservado à escola não só na época, mas em períodos posteriores: é necessário que ela promova a educação dos trabalhadores e seus filhos, ainda que, potencialmente, tal fato possa representar ameaça à própria classe social que a estimula.

Daí sua disponibilização sob controle, seja no âmbito educacional, seja no produtivo. Naquele, pela definição do que ensinar e do tipo de educação a oferecer. Neste, pela organização da produção de modo que o saber dominado pelo trabalhador se restrinja ao que é funcional a esta, enquanto que os que a estruturam detêm o saber sobre o processo produtivo como um todo. Tal controle e restrição são favorecidos pela incorporação da ciência à produção fabril, principalmente a partir da revolução industrial, sob a forma da maquinaria que, tornando-se mais sofisticada, permite a simplificação do trabalho, acentuando o caráter manual da intervenção humana no processo e, por consequência, solicitando menos dos trabalhadores a utilização de seus recursos mentais. À evolução técnica da maquinaria correspondeu, portanto, a involução em termos de qualificação específica, bastando aos trabalhadores aquela de caráter geral fornecida pela escola primária. Qualificações específicas necessárias à manutenção do maquinário passaram a ser desenvolvidas pela formação profissional em cursos oferecidos pelas empresas ou por escolas destinadas a tal fim, produzindo-se, por essa forma, tanto a expansão escolar quanto sua divisão em termos de formação geral e específica. A própria simplificação do trabalho por meio da maquinaria justificaria a célebre assertiva de Adam Smith de que o trabalhador fabril deveria, em benefício da sociedade e da produção, ser educado, mas... em doses homeopáticas. 
Tal encaminhamento contraditório não é tranquilo para a própria burguesia que, não por razões humanitárias, mas políticas, percebe a necessidade de promover a unificação escolar. Machado (1989) produz um interessante texto a respeito, explorado aqui de forma parcial e rápida por razões de espaço. A autora examina a proposta de unificação escolar liberal no contexto das discussões sobre o espírito e unidade nacionais, travadas no decorrer dos séculos XVIII e XIX, as quais se originam no interesse da burguesia em constituir uma vontade nacional, articulada em torno do Estado, tendo por base suas concepções de mundo, ou, em outros termos, produzir uma uniformidade cultural e ideológica que lhe permitisse tornar-se hegemônica.

Tal movimento, que se estende a vários países europeus, é particularmente forte na Alemanha em função das disputas de interesse entre a burguesia, a igreja, a monarquia e a nobreza no que respeitava à unificação alemã. A educação nacional proposta por Fichte, ideólogo da unificação alemã, no decorrer da primeira década do século XIX, torna-se parte desse debate de forma contraditória, pois este filósofo defende, simultaneamente, que o Estado deve promover a união entre o estudo e o trabalho e estabelecer distinção entre a formação do 'sábio' e dos demais homens na medida em que, de acordo com o ideário liberal, nem todos teriam aptidões para as atividades intelectuais.

Esse argumento, associado à histórica divisão social do trabalho e à intensificação da divisão técnica do trabalho a partir da Revolução Industrial, tornar-se-á a pedra de toque para justificar, de um lado, a concepção de que, sob o liberalismo, não deveriam existir discriminações de qualquer natureza no que tange ao acesso à educação e, de outro, a separação entre o trabalho intelectual e o trabalho manual e, portanto, da educação daqueles que se dirigissem a um ou a outro.

De acordo com Machado,

O projeto burguês de escola unificada pretende realizar a unificação escolar pela supressão das barreiras econômicas, políticas, religiosas, raciais e sexuais existentes ao acesso à escola, condicionando-o apenas a critérios psicopedagógicos. Advoga, também, realizar através dessa unificação a unidade nacional, infundindo um mesmo sentimento pátrio, a identificar moral e culturalmente todo o povo (Machado, 1989, p. 107).

Dessa forma, "o que faz o projeto liberal", no dizer de Machado, "é transpor para o plano educacional o limitado horizonte do direito burguês" (Machado, 1989, p. 95). Segundo essa mesma autora,

Esse objetivo, no entanto, seria inalcançável, segundo a teoria marxista, no âmbito da sociedade burguesa por entrar em conflito com o estado econômico vigente, 
caracterizado por profundas contradições entre as classes sociais, que teriam objetivos completamente opostos (...) impedindo na prática (e contradizendo os princípios ideológicos por ela apregoados) a igualdade de direito e liberdade de escolha (Machado, 1989, p. 93-94).

Percebe-se, pois, que a escola 'única' proposta pela burguesia não significa o mesmo que a educação integral, objeto do enfoque socialista. Não obstante, de acordo com Machado, os trabalhadores viam no sistema escolar unificado uma medida de democratização do acesso à educação e o reivindicavam.

\section{As concepções socialistas sobre a escola}

Nesta parte do texto serão examinadas, de forma separada e, posteriormente, articulada as concepções de Marx/Engels e de Gramsci a respeito da educação escolar. A razão para essa separação reporta-se ao reconhecimento, na literatura, de que há, entre ambas as proposições, identificações e distanciamentos, as primeiras por conta da matriz teórica e os segundos devido ao contexto histórico em que foram pensadas. Nesse sentido, a discussão sobre a politecnia e a escola unitária será remetida aos respectivos contextos históricos em que tais proposições foram feitas para evitar sua reificação, de modo a que sejam entendidas como inspiração e não como receitas.

\section{A concepção marxiana sobre a educação}

Para o exame da produção marxiana que pode ser legitimamente referida à educação, recorrerei principalmente aos trabalhos de Machado (1989) e Nogueira (1990) por considerar que fazem um bom apanhado das preocupações de Marx e Engels a respeito no decorrer do século XIX. É necessário, para o bom entendimento do tema, reter que tanto Marx quanto Engels, e depois Gramsci, não pensaram a educação numa perspectiva meramente técnico-pedagógica, mas eminentemente histórico-política, a qual tem por referência principal o embate de classes na sociedade capitalista. Por essa razão é necessário, tanto num caso quanto no outro, situar o contexto histórico em que a educação e a escola foram pensadas na perspectiva do materialismo histórico.

À concepção liberal da escola 'única', dadas as suas limitações e os interesses de classe que a sustentavam, contrapuseram-se os socialistas (utópicos e científicos), seja por meio de associações operárias, seja por meio de experiências como as de Robert Owen, ou por meio da produção teórica. Nesse último caso ganha relevo a produção de Marx e Engels. 
A experiência do socialista utópico Owen, desenvolvida nas colônias de New Lanark (Inglaterra), entre 1800 e 1829, e New Harmony (EUA), entre 1825 e 1827, é reputada por Suchodolski (1976, apud Machado, 1989) como uma das primeiras manifestações das preocupações socialistas com a educação dos filhos dos trabalhadores na perspectiva não liberal de unificação de estudo e trabalho. Co-proprietário de uma indústria têxtil na Inglaterra, Owen, instigado pela crença de que os males sociais deveriam ser tributados à ignorância e pouca instrução da população e inspirado por seus ideais filantrópicos, adota medidas inovadoras em relação ao trabalho e à educação das crianças que trabalhavam em suas fábricas. Nestas, introduz formas de gestão cooperativa, diminui a jornada de trabalho de seus operários e lhes eleva os salários.

No que se refere à educação das crianças, coloca em prática suas convicções de que a união entre educação e trabalho teria grande valor educativo, se tomado por base o trabalho na perspectiva moderna e não na produção artesanal. Defenderá, por essa forma, a divisão diária do tempo das crianças entre o trabalho na fábrica e a frequência à escola, medida que Marx elogiará e incorporará como elemento central nos textos em que trata da educação dos filhos de trabalhadores, sem deixar de lado, todavia, as críticas que fez aos socialistas utópicos. Como assevera Nogueira, apesar de Marx e Engels entenderem o pensamento utópico como uma necessidade que corresponderia a "um momento de imaturidade do capital e da luta de classes" (Nogueira, 1990, p. 103), percebiam-no como

um empecilho ao desenvolvimento do movimento operário e que se tornava, portanto, necessário derivar a teoria não mais de condenações morais fundadas sobre os princípios a-históricos de justiça, igualdade, etc. que vão dar na construção imaginária de sistemas sociais perfeitos e acabados, mas sim de análises científicas da realidade social (Nogueira, 1990, p. 103).

É exatamente por esse caminho que Marx produzirá, na perspectiva do materialismo histórico, não apenas sua análise do desenvolvimento do capitalismo, mas também das propostas burguesas da união escolar, criticandoas em face das condições objetivas de escolarização e trabalho determinadas pela estrutura da produção fabril de então, que atingiam duramente as famílias dos operários e seus filhos. Em função disso, suas discussões sobre a educação terão sempre por referência as condições políticas, econômicas e sociais em que se dá o trabalho fabril em sua época, as quais vão propiciar o crescimento do processo de acumulação capitalista e, contraditoriamente, intensos movimentos trabalhistas de recusa a tais condições, o que torna o período particularmente violento, dando margem às revoluções e embates que o marcam, configurando o que Gramsci denominará de 'guerra de 
movimento'. Assim, se o pensamento utópico de Owen a respeito da educação tem uma forte influência sobre Marx, é a análise científica que este realiza da produção capitalista de seu tempo que conferirá densidade teórica às suas proposições educacionais.

Nessa perspectiva, segundo Machado (1989, p. 88), além de abordar a educação no Manifesto Comunista de 1848, “Marx e Engels [dela tratam] n'A ideologia alemã (1845/46), na Instrução aos delegados para o I Congresso Internacional dos Trabalhadores (1866), no primeiro volume de $O$ capital (1867) e na Critica ao Programa de Gotha (1875)".

Nogueira (1990, p. 106) assinala, no entanto, que uma das primeiras menções à 'união do ensino com o trabalho produtivo' aparecerá nos Princípios do comunismo, produzido por Engels em 1847, por solicitação da Liga dos Comunistas que havia sido criada em Londres pouco antes, representando, segundo esta autora, mudança de opinião em relação à posição assumida por Engels na redação de $A$ situação da classe trabalhadora na Inglaterra, de 1844, quando, em face do processo de exploração do trabalho infantil, mostrava-se contrário à utilização de crianças na produção. A mesma proposição de união entre ensino e trabalho reaparecerá no texto de Marx e Engels do Manifesto do Partido Comunista, a par da proposição da educação pública e gratuita e da abolição do trabalho infantil nas fábricas, nas condições até então praticadas. Tal proposta é retomada nas manifestações de Marx junto à Associação Internacional de Trabalhadores (AIT), tendo em vista o congresso da instituição realizado em Genebra, em 1866, e a preparação do congresso a ser realizado na Basiléia, em 1869. Na primeira delas, Marx reafirma que o trabalho infanto-juvenil somente poderia ser admitido se articulado com a educação. Na segunda, estipula, com maior clareza, em que consistiria tal articulação, indicando a necessidade de que se combinasse "o ensino intelectual com o trabalho físico, os exercícios ginásticos com a formação politécnica" (Marx e Engels, 1976, apud Nogueira, 1990, p. 109). Em nenhum momento encontra-se em Marx a proposta de que as crianças deixem de participar do trabalho fabril, mas sim que ele se dê em condições mais salubres e de acordo com os diferentes níveis de idade e, necessariamente, associado ao estudo, exatamente por acreditar que a combinação entre um e outro constituiria em elemento central para a educação da classe operária. Aliás, é com base nessa convicção que fará sua crítica, do ponto de vista educacional, ao Programa de Gotha, por meio do qual a Associação Geral dos Trabalhadores Alemães, fundada por Lassale, e o Partido Operário Social-Democrata da Alemanha, então disputando a hegemonia do operariado, pretendiam, em 1875, promover sua união. O referido Programa, como salienta Nogueira (1990, p. 111), "não somente deixou de incluir entre as suas reivindicações a união da instrução com o trabalho, mas, pior que isso, chegava mesmo a pregar (sob a influência da facção lassaliana) a supressão do trabalho da criança". 
Se até esse momento a articulação entre produção e ensino se faz presente nos textos desses autores, sob a forma de um dos pontos a ser desenvolvido tendo em vista uma sociedade futura, em $O$ capital tal articulação é encarada claramente como resultado do processo contraditório de desenvolvimento da produção capitalista. Em outros termos, a educação, com tais características, se apresenta como uma demanda do próprio capital em seu processo de acumulação, cabendo aos trabalhadores, como coletivo, interferir com suas reivindicações e exigências de modo não só a apressá-lo como, também, no sentido de fazê-lo de acordo com os seus interesses, ainda que limitados pelo capital. Trata-se, portanto, de captar, no seio das contradições da produção capitalista, os elementos de uma nova organização social cuja possibilidade é posta por estas mesmas contradições. É dessa perspectiva que Marx entende o avanço representado pelas leis fabris de 1833 e 1864, apesar de suas limitações, tendo em vista o momento histórico em que surgem, na medida em que, do ponto de vista político, fortalecem a perspectiva de união entre o estudo e o trabalho, ainda que com restrições, para os filhos dos trabalhadores que, em grande proporção, estavam submetidos todo o tempo apenas ao trabalho repetitivo e degradante. A longa citação abaixo é suficientemente enfática para não deixar dúvidas a respeito:

A indústria moderna, com suas próprias catástrofes, torna questão de vida ou morte reconhecer como a lei geral e social da produção a variação dos trabalhos e em consequência a maior versatilidade possível do trabalhador, e adaptar as condições à efetivação normal dessa lei. Torna questão de vida ou morte substituir a monstruosidade de uma população operária miserável, disponível, mantida em reserva para as necessidades flutuantes da exploração capitalista, pela disponibilidade absoluta do ser humano para as necessidades variáveis do trabalho; substituir o indivíduo parcial, mero fragmento humano que repete sempre uma operação parcial, pelo indivíduo integralmente desenvolvido para o qual as diferentes funções sociais não passariam de formas diferentes e sucessivas de sua atividade. As escolas politécnicas e agronômicas são fatores desse processo de transformação, que se desenvolveram espontaneamente na base da indústria moderna; constituem também fatores dessa metamorfose as escolas de ensino profissional onde os filhos dos operários recebem algum ensino tecnológico e são iniciados no manejo prático dos diferentes instrumentos de produção. A legislação fabril arrancou ao capital a primeira e insuficiente concessão de conjugar a instrução primária com o trabalho na fábrica (Marx, s/d, p. 558-559).

A citação poderia ser interpretada como evolucionista, no sentido de que, deixado ao próprio curso e em vista das contradições que o permeiam, o desenvolvimento do capitalismo o conduziria a uma formação social superior. Não é esse certamente o pensamento de Marx que, ciente de que 
continuidade e ruptura são parte do mesmo processo, defenderá que as lutas operárias tenham por meta a ruptura, mas por referência as condições concretas existentes. Daí a razão de considerar um avanço as leis fabris, apesar de suas limitações.

Tal enfoque conduz à perspectiva de constituição de um outro trabalhador que, diferentemente do operário parcelar, preso à realização de atividades produtivas detalhadas, pudesse fazer face às novas configurações da fábrica antevistas por Marx, desenvolvendo, nos limites das possibilidades concretas, a capacidade de ampliar o escopo de seu trabalho. Além disso, Marx entrevia na união do ensino com o trabalho a possibilidade do aumento da produtividade e, com isto, a perspectiva de aumento do tempo livre que poderia contribuir para o desenvolvimento superior do homem, ainda que, realisticamente, tivesse clareza de que o capital buscaria aproveitar todo o tempo disponível do trabalhador em benefício da acumulação. "Na concepção de Marx", conforme assevera Machado (1989, p. 126),

o ensino politécnico, de preparação multifacética do homem, seria o único capaz de dar conta do movimento dialético de continuidade-ruptura, pois não somente estaria articulado com a tendência histórica de desenvolvimento da sociedade, como a fortaleceria. O ensino técnico seria, por isso, fermento da transformação: contribuiria para aumentar a produção, fortalecer o desenvolvimento das forças produtivas e intensificar a contradição principal do capitalismo (entre socialização crescente da produção e mecanismos privados de apropriação). Por outro lado, contribuiria para fortalecer o próprio trabalhador, desenvolvendo suas energias físicas e mentais, abrindo-lhe os horizontes da imaginação e habilitando-o a assumir o comando da transformação social (Machado, 1989, p. 126).

Elemento básico nessa proposição é a concepção do trabalho como constituinte do ser social, ainda que na sociedade capitalista assuma, contraditoriamente, dimensões alienantes. Central, também, é a perspectiva de que o ensino politécnico enseja a relação teoria e prática, assim como o acesso das crianças aos conhecimentos científicos e tecnológicos que servem de fundamento à produção fabril, por meio de processos de simplificação que reduzam mecanismos complicados a seus princípios básicos, contribuindo, desta forma, para a formação multilateral dos trabalhadores.

Com base nesses pressupostos, em um texto redigido por Marx para o congresso da Associação Internacional dos Trabalhadores, realizado em Genebra em 1866, denominado Instruções aos delegados do Conselho Central Provisório acerca de diversas questões, explicita-se seu entendimento do que constituiria a educação voltada para os filhos de operários: a) educação mental; b) educação corporal, tal qual é produzida pelos exercícios ginásticos e militares; e c) educação tecnológica, compreendendo os princípios 
gerais e científicos de todos os processos de produção e, ao mesmo tempo, iniciando as crianças e os adolescentes no manejo dos instrumentos elementares de todos os ramos industriais.

Os elementos dessa educação deveriam ser disponibilizados aos filhos dos trabalhadores de acordo com três categorias de idade: nove a 12 anos; 13 a 15 anos; e 16 e 17 anos, cuja ocupação em atividades produtivas seria, respectivamente, de duas, quatro e seis horas diárias.

Cabe esclarecer o que Marx e Engels entendem por esses diferentes componentes. No que respeita à 'educação mental', sem entrar nas dissensões entre Marx e Engels a respeito do desenvolvimento de uma educação especificamente proletária, interessa destacar, conforme Nogueira (1990, p. 159 e ss.), que Marx tendeu, de um lado, a descartar a proposição de Engels de desenvolvimento de uma educação engajada, argumentando que isto caberia ao espaço da luta política, devendo realizar-se fora da escola e, de outro, a privilegiar disciplinas como a gramática e as ciências naturais, ou seja, conteúdos de formação intelectual que não tivessem por objetivo explícito questões de ordem ideológica.

Nogueira estranha essa postura de Marx, identificando-a com um viés 'neutralista' em termos dos conteúdos das ciências, mas a seguir adenda, conferindo-lhe outra interpretação, que ela talvez se devesse ao fato de que, por volta de 1860, o movimento operário disperso e desorganizado do início do século desenvolvera maior organicidade, estando em condições de assumir a formação política da juventude. Minha hipótese é algo diversa, embora a apresentada acima faça sentido. Parece-me que a indicação de Marx pode ser interpretada como parte de sua preocupação de que os trabalhadores e suas famílias tivessem acesso ao acervo de conhecimento então disponível, ainda que de extração burguesa, na medida em que este conhecimento é que lhe permitiria melhor compreender o processo produtivo, fortalecendo-o nas disputas políticas.

Quanto à 'educação física', nem Marx, nem Engels fizeram recomendações detalhadas. Ressalta em Marx a preocupação de incluí-la no currículo escolar, tendo em vista sua contribuição para a recuperação física das crianças, extenuadas pelas longas horas de trabalho na fábrica. Nogueira (1990, p. 167-169) sugere que a preocupação com o cuidado do corpo era partilhada por outros em sua época, com a finalidade de disciplinar o corpo. Quanto aos exercícios militares, também preconizados por Marx, essa autora lembra que, à época, existia uma forte relação entre a ginástica e tais exercícios.

A 'educação tecnológica' é, dos três componentes, o que tem sido mais frequentemente ressaltado, provavelmente por estar ligado, de forma cabal, ao argumento de Marx de que, para organizar e controlar a produção seria necessário aos operários deter saberes que, contidos nas máquinas, ultrapassariam de muito aqueles necessários apenas ao manejo delas, o que se 
acentuaria ainda mais em períodos futuros com o avanço da tecnologia. Essa dimensão do processo educativo é particularmente importante na proposição marxiana, pois é pela sua mediação que, com maior propriedade e organicidade, pode ser produzida a relação teoria e prática, trabalho intelectual e trabalho manual, ensino e trabalho.

Tal dimensão implicaria, de um lado, o conhecimento das bases científicas dos diferentes processos produtivos, ou seja, seus princípios, e de outro, sua aplicação por meio dos instrumentos elementares utilizados nestes processos. Para Marx, conduzir as crianças e jovens ao domínio de tal conhecimento não representaria tarefa por demais complexa, dado que o desenvolvimento da tecnologia, naquele momento histórico, se apoiaria em um número restrito de princípios científicos que orientariam a produção de uma multiplicidade de instrumentos e mecanismos.

A insistência de Marx na educação tecnológica também está referida à clareza que tinha de que a união entre trabalho e educação proposta pela burguesia remetia ao ensino profissional estreito, que visava tão-somente ao preparo adequado para o desempenho de tarefas estritamente técnicas. Apesar da importância que conferia a essa dimensão do ensino, não escapava a Marx a noção de que somente o domínio dos princípios técnicos da produção seria insuficiente para o controle produtivo, cuja efetivação dependeria de mudanças radicais nas relações de produção.

\section{A concepção de educação em Gramsci}

Tal qual ocorreu no exame da concepção educacional em Marx e Engels, parte-se de uma contextualização do pensamento gramsciano para, em seu interior, abordar a questão da educação.

Não é possível discutir adequadamente a concepção de Gramsci sobre a educação sem situá-la, imediatamente, no âmbito de suas preocupações sobre hegemonia e luta hegemônica. O aspecto que ressalta no tratamento que Gramsci confere ao conceito de hegemonia é o de sua vinculação concreta com o problema da luta de classes no plano da sociedade capitalista, tal como o fizera Lênin.

Tal interpretação da luta pelo poder decorre do questionamento, por parte de Gramsci, das teses estritamente economicistas de superação do capitalismo, bem como da efetividade da 'guerra de movimento', por não encontrar nelas elementos que lhe permitiriam explicar por que, apesar da crise econômica aguda e da situação teoricamente favorável à revolução socialista existente na Itália e em vários países da Europa Ocidental das décadas de 1920 e 1930, ela não ocorre como acontecera na Rússia, favorecendo, ao contrário, o desenvolvimento do fascismo. Em decorrência, tenta encontrar res- 
postas nos aspectos políticos e ideológicos do marxismo, sem descartar, todavia, a tomada do poder pelas armas.

Por esse processo elabora teoricamente a distinção entre 'sociedades orientais' e 'sociedades ocidentais'. Nas primeiras, por serem política e ideologicamente menos complexas, as crises econômicas irromperiam catastroficamente na superestrutura. Nas segundas, em função de sua complexidade nos planos político e ideológico, tal não ocorreria, dada a mediação do conjunto de organismos da sociedade civil, por meio dos quais a classe burguesa difunde sua concepção de mundo.

Mais que isso, dada a sua desconfiança em relação ao enfoque economicista do processo de superação do capitalismo, Gramsci questionará a determinação da superestrutura pela infra-estrutura produtiva, afirmando a autonomia relativa daquela em relação a esta, ao mesmo tempo em que ressaltará a relação dialética entre estas duas instâncias e o caráter material e não apenas funcional da ideologia em relação à sociedade política. A necessidade, por parte das classes sociais fundamentais (a burguesia e o proletariado) de obter o consenso em torno das posições políticas e ideológicas que defendem, cria ou renova objetivações sociais (ou organismos sociais) que funcionam como portadores materiais específicos das relações sociais de hegemonia, contando com estrutura e legalidade próprias. Essa independência relativa permite à sociedade civil atuar como mediação necessária entre a base econômica e o Estado em sentido estrito (sociedade política). É esse o campo em que se travam as batalhas da 'guerra de posição', visando a produzir a 'reforma intelectual e moral' naqueles setores sociais que são objeto da disputa hegemônica, ou seja, mudanças na forma de conceber o mundo (reforma intelectual) e na forma de conduzir-se coerentemente com tal concepção (reforma moral).

Essa elaboração se torna possível por estar apoiada em outra construção teórica, a concepção ampliada de Estado, calcada na observação e análise da participação política intensa e diversificada que, nas décadas de 1920 e 1930, ocorria nos países da Europa Ocidental. De acordo com essa concepção, Gramsci identifica no interior do Estado a sociedade política, composta pelo conjunto dos mecanismos por meio dos quais a classe dominante detém o monopólio legal da violência e, de outro lado, a sociedade civil, constituída pelo conjunto das organizações responsáveis pela elaboração e divulgação ideológica (escolas, igreja, partidos políticos, meios de comunicação etc.) de "seu modo de viver e pensar, suas aspirações, moralidade e hábitos [estabelecendo sua] 'hegemonia', isto é, sua supremacia intelectual e moral sobre a grande massa de cidadãos que (...) anuem, com graus variados de entusiasmo, ao estado de coisas" (Femia, 1979, p. 150).

A anuência da 'massa de cidadãos' ao 'estado de coisas' com "variados graus de entusiasmo' sugere a presença, em tal massa, de possibilidades de 
negação e resistência ou, em outros termos, que a 'interiorização' dos valores burgueses por parte dos trabalhadores não é necessariamente inevitável em sua plenitude. Não obstante, tanto quanto o movimento de aceitação, o de negação pode se dar de forma dispersa, desarticulada, segmentada, baseada mais no senso comum do que na compreensão clara do 'estado das coisas', ainda que, de acordo com Gramsci, os movimentos populares sejam os 'fermentos' da renovação cultural.

Por isso Gramsci considera necessária a criação de uma cultura que seja síntese de 'culturas de massa'. O que orienta esse enfoque é a convicção de que a construção de uma perspectiva transformadora (ou seja, de uma contrahegemonia) depende da construção da unidade entre pensamento e ser, entre filosofia e política, teoria e prática, de modo a ser possível produzir a conversão da ideologia em 'vontade coletiva' (unidade cultural e social orientadora da ação), mas uma vontade coletiva nascida da história, ou seja, construída a partir dos problemas concretamente postos a uma sociedade no seu desenvolvimento histórico. No entender de Gramsci, o marxismo reuniria as condições para promover a reforma intelectual e moral das massas, devendo sua difusão ser realizada articuladamente com o trabalho desenvolvido pelos setores populares.

É necessário destacar que Gramsci não atribui à cultura o significado positivista, presente no senso comum, que a identifica com a posse de conhecimentos enciclopédicos sobre os mais diversos assuntos. Diversamente, concebe-a como organização e disciplina interior de uma personalidade que é, ela própria, uma construção histórica. Tal organização e disciplina implicam a capacidade e disposição do indivíduo de enfrentar-se com algo que entende como estranho a si mesmo (uma crença ou senso comum) e, de frente a este elemento estranho, construir um modo próprio e mais elaborado de pensá-lo e de agir em relação a ele. Tal construção é entendida como um ato político pelo qual o homem se liberta das peias do pensamento mágico para pôr-se como centro e responsável por suas ações.

Considerando que a construção da 'vontade coletiva' é um processo longo e espinhoso, a ação cultural sistemática deverá, nesta perspectiva, exercer o papel político de fazer a crítica das ideologias dominantes e a construção, a partir dela, de novas ideologias que sejam expressão da concepção proletária de mundo. De outro lado, cabe-lhe promover a divulgação dessas ideologias (no caso, o marxismo) pelas mais diversas formas, instrumentos e organismos. O próprio Gramsci dedicou sua vida à prática dessa proposição, seja como teórico, jornalista ou militante partidário, coerentemente com as recomendações abaixo:

1) não se cansar de repetir os próprios argumentos (variando literariamente a sua forma): a repetição é o meio didático mais eficaz para agir sobre a mentalidade 
popular; 2) trabalhar incessantemente para elevar intelectualmente camadas populares cada vez mais vastas, isto é, para dar personalidade ao amorfo elemento de massa, o que significa trabalhar na criação de elites de intelectuais de novo tipo, que surjam diretamente da massa e que permaneçam em contato com ela para tornarem-se seu sustentáculo (Gramsci, 1978, p. 27).

As 'elites intelectuais', ou os intelectuais orgânicos² a que se refere Gramsci, constituem um elemento central no processo de elaboração filosófica das questões e problemas, dos rumos e perspectivas descortinados pelo movimento social, tanto quanto na sua difusão. Incumbe-lhes, nesse sentido, em articulação com intelectuais de diferentes camadas, realizar o processo de

desarticular dos interesses dominantes aqueles que estão articulados em torno deles, mas não são inerentes à ideologia dominante [e, simultaneamente, rearticulá-los em torno dos interesses das classes dominadas] dando-lhes a coesão, a coerência e a consistência, de uma concepção de mundo elaborada, vale dizer, de uma filosofia (Saviani, 1980, p. 11).

Trata-se, do ponto de vista da transformação social, de desarticular um bloco histórico e, simultaneamente, desencadear ações político-culturais cujo objetivo é o de articular um novo bloco histórico. O caráter político cultural dessas ações é fundamental para a desarticulação acima referida, implicando a participação consciente da classe trabalhadora, conseguida pela superação de suas concepções fragmentárias, caóticas, incoerentes e pouco realistas do mundo. Por seu turno, tal superação não resulta de ações de caráter meramente especulativo, mas de um refletir sobre a prática de uma práxis política. Ao intelectual orgânico da classe trabalhadora, individual ou coletivo, caberá a árdua tarefa de contribuir decisivamente para que esse processo ocorra.

No entanto, é necessário considerar que, no plano da sociedade concreta, a elevação do nível cultural das massas é condição necessária, mas não suficiente, para que se constitua um novo bloco histórico. Outras determinações devem se fazer simultaneamente presentes para que a luta hegemônica se instale e se desenvolva. Assim, algumas condições estruturais devem estar em curso ou devem existir, pelo menos em parte, dado que: a) nenhuma sociedade assume encargos para cuja solução não existem condições necessárias e suficientes, ou que pelo menos não estejam em vias de aparecer e se desenvolver; b) nenhuma sociedade se dissolve e pode ser substituída antes de se desenvolver e completar todas as formas de vida implícitas em suas relações (Gramsci, 1978a, p. 45).

Tais condições ocorrem tão-somente no curso da crise orgânica que resulta da ruptura dos laços existentes entre estrutura e superestrutura, por 
força das contradições geradas pelas próprias formas econômicas da estrutura ou mesmo, simultaneamente, pela ação desagregadora desencadeada contra as classes dominantes por parte das classes subalternas. É no bojo de tal crise que essas últimas devem tentar fortalecer sua posição e interesses, já que a mera explosão das contradições capitalistas não as conduzirá, automaticamente, à conquista do poder. Esse fortalecimento político cultural é fundamental, dado que o novo bloco histórico não se constitui repentina e linearmente, mas é realidade que vai se construindo dialeticamente no curso da própria luta, por meio de alianças de classe, da desarticulação do bloco intelectual orgânico da classe dominante, da atração dos intelectuais tradicionais existentes no seio da sociedade, da elaboração e difusão, no interior da classe dominada, de uma concepção articulada, coerente, intencional e ativa do mundo.

Por considerar a escola uma das organizações da sociedade civil responsáveis pela elaboração e divulgação de ideologia, Gramsci lhe conferirá especial atenção, assim como o fez em relação ao partido político, à imprensa e à igreja. Nesse sentido percebe nela tanto a possibilidade de reiteração da concepção de mundo das classes dominantes, quanto a de atuação no sentido de contribuir para a reforma intelectual-moral da massa trabalhadora tendo por horizonte a superação da sociedade capitalista. Na perspectiva da luta hegemônica à escola caberia promover a educação das massas populares com o objetivo de libertá-las da visão folclórica de mundo e dos mitos, tendo em vista a construção de uma consciência unitária.

Cabe, portanto, examinar como a educação é entendida por Gramsci. Para tal nos valeremos de seus escritos em Os intelectuais e a organização da cultura, bem como da contribuição de autores que discutem suas proposições. O ponto de partida parece-nos ser o reconhecimento, por parte de Gramsci, da crise pela qual estaria passando a escola 'clássica', a qual seria reflexo da crise mais ampla da sociedade em função das transformações ocorridas no campo do trabalho e da vida política, social e cultural que vinham minando, desde o desenvolvimento da grande indústria capitalista, as sociedades anteriormente organizadas em bases feudais e aristocráticas. Tal desenvolvimento histórico criou "a necessidade de um novo tipo de intelectual urbano" (Gramsci, 1979, p. 118), colocando em questão “o próprio princípio da orientação concreta de cultura geral, da orientação humanista da cultura geral fundada sobre a tradição greco-romana" (Gramsci, 1979, p. 118).

Nesse sentido, Gramsci chamará a atenção para a tendência crescente de abolição da escola de cultura geral "desinteressada" e formativa e, concomitantemente, para a crescente proliferação das "escolas profissionais especializadas, nas quais o destino do aluno e sua futura atividade são predeterminados" (Gramsci, 1979, p. 118). Nessa mesma linha, argumentará que 
na escola atual, graças à crise profunda da tradição cultural e da concepção da vida e do homem, verifica-se um processo de progressiva degenerescência: as escolas de tipo profissional, isto é, preocupadas em satisfazer interesses práticos imediatos, tomam a frente da escola formativa, imediatamente desinteressada. $\mathrm{O}$ aspecto mais paradoxal reside em que este novo tipo de escola aparece e é louvada como democrática, quando, na realidade, não só é destinada a perpetuar as diferenças sociais, como ainda a cristalizá-las em formas chinesas (Gramsci, 1979, p. 136).

Tal tipo de observação não tem conotação moral, no sentido de crítica ao desenvolvimento da sociedade industrial, posto que este é entendido por Gramsci como historicamente necessário. Objeto de sua preocupação são, de um lado, os desdobramentos político-ideológicos e culturais desse desenvolvimento e, de outro, a orientação político-ideológica que cabe aos intelectuais orgânicos comprometidos com a luta hegemônica dos trabalhadores no sentido de contra-restar tal desenvolvimento, dado que, como aponta Nosella (1991, p. 141) é-lhe claro que “a racionalidade, o ritmo, a dinâmica, as leis dessa nova forma de trabalho moldam aos poucos, inexorável e molecularmente, os homens e as instituições da sociedade moderna". Gramsci evidenciará isso em dois comentários a respeito. No primeiro, chamará a atenção para a tendência de

cada atividade prática (...) criar para si uma escola especializada própria, do mesmo modo como cada atividade intelectual tende a criar círculos próprios de cultura, que assumem a função de instituições pré-escolares especializadas em organizar as condições nas quais seja possível manter-se a par dos progressos que ocorrem no ramo científico próprio (Gramsci, 1979, p. 119).

No segundo, apontará para a tendência de órgãos deliberativos existentes no corpo social de se orientarem não apenas por ações de tal natureza, mas de caráter técnico-cultural, a cargo de especialistas, constituindo grupos de influência nas decisões e atividades políticas. Considerando que as tentativas de contrapor-se 'de fora' a tais desenvolvimentos tenderá a transformar-se em 'pregações moralistas', defenderá a preparação de novos dirigentes que tenham

aquele mínimo de cultura geral que lhe(s) permita, senão 'criar' autonomamente a solução justa, pelo menos saber julgar entre as soluções projetadas pelos especialistas e consequentemente escolher a que seja justa do ponto de vista 'sintético' da técnica política (Gramsci, 1979, p. 119-120).

Para o enfrentamento da crise e sua solução, proporá que a educação se dê por intermédio da 
escola única inicial de cultura geral, humanista, formativa, que equilibre equanimemente o desenvolvimento da capacidade de trabalhar manualmente (tecnicamente, industrialmente) e o desenvolvimento das capacidades de desenvolvimento intelectual. Deste tipo de escola única, através de repetidas experiências de orientação profissional, passar-se-á a uma das escolas especializadas ou ao trabalho produtivo (Gramsci, 1979, p. 118).

Em outros termos,

a escola unitária ou de formação humanista (entendido este termo, 'humanismo', em sentido amplo e não apenas no sentido tradicional) ou de cultura geral deveria se propor a tarefa de inserir os jovens na atividade social, depois de tê-los levado a um certo grau de maturidade e capacidade, à criação intelectual e prática e a uma certa autonomia na orientação e na iniciativa (Gramsci, 1979, p. 121).

Compreendendo os níveis primário e médio, a escola unitária, ou de formação humanista, deveria dedicar-se, no primeiro, ao ensino de noções 'instrumentais' de redação e escrita, aritmética, aprendizagem das leis naturais, bem como das noções de 'direitos e deveres', tendo em vista difundir "uma nova concepção do mundo", em substituição às concepções folclóricas. A fase correspondente ao nível médio deveria

ser concebida e organizada como a fase decisiva, na qual se tende a criar os valores fundamentais do 'humanismo', a autodisciplina intelectual e a autonomia moral necessárias a uma posterior especialização, seja ela de caráter científico (estudos universitários), seja de caráter imediatamente prático-produtivo (indústria, burocracia, organização das trocas etc.) (Gramsci, 1979, p. 124).

Entendendo a escola unitária como ativa (um conceito a ser examinado na discussão do princípio educativo), Gramsci recomendará, para o desenvolvimento dos trabalhos nessa última fase, "o estudo e o aprendizado dos métodos criativos na ciência e na vida", constituindo-se a "escola criadora o coroamento da escola ativa" (Gramsci, 1979, p. 124). De acordo com Gramsci:

Na primeira fase tende-se a disciplinar, portanto, também a nivelar, a obter uma certa espécie de conformismo "dinâmico"; na fase criadora, sobre a base já atingida de "coletivização" do tipo social, tende-se a expandir a personalidade, tornada autônoma e responsável, mas com uma consciência moral e social sólida e homogênea (Gramsci, 1979, p. 124).

Partindo da concepção de que o caráter unitário decorre tanto de sua organização quanto do princípio formativo que a estrutura, Gramsci tomará 
como tal princípio o conceito e o fato do trabalho, entendido na sua perspectiva ontológica, como mediador da relação homem-natureza e das relações entre os homens na vida social. A compreensão histórica desse processo implica, de um lado, o conhecimento das leis naturais (societas rerum) e, de outro, o conhecimento do ordenamento jurídico da vida social, construído historicamente pelas sociedades para organizá-las tendo em vista a relação homem-natureza e dos homens entre si (societas homninum). Deve-se considerar que esse tipo de aproximação educativa, de acordo com Manacorda (1977), já estava presente nas escolas elementares italianas na forma como foram estruturadas antes da reforma Gentili, o qual, segundo Gramsci, as havia "colocado numa espécie de limbo" (Gramsci, 1979, p. 129). Daí sua proposição de que a escola se volte, de um lado, para o desenvolvimento das noções científicas que permitiriam não só a libertação das noções folclóricas do mundo, das crenças e dos mitos, mas também a clareza de que tais noções se desenvolveram em resposta à necessidade humana de defrontarse com a natureza e, de outro, para as noções relativas à vida em sociedade, resultante histórica desse mesmo processo, implicando a elaboração de normas e regras sociais, definição de direitos e deveres. Enfim, o conhecimento da vida social e suas determinações, mediadas pelo trabalho.

Nesse sentido distancia-se, conforme Soares (2000), tanto da concepção liberal-burguesa de articulação entre a formação geral e o trabalho, orientada pelas proposições da escola nova, em que o trabalho, na perspectiva de Kershensteiner, é entendido sob a forma de 'atividade', quanto da perspectiva socialista da escola única do trabalho que assume, no ponto de partida, o conceito marxiano de trabalho como categoria histórica, mas que acaba por reduzi-lo ao trabalho fabril. As aproximações e distanciamentos entre as concepções de Marx-Engels e Gramsci sobre a integração trabalho-educação geral serão tratadas posteriormente. Por ora, é importante recuperar a concepção de atividade em Gramsci com base em Soares, dado que é a partir dela que se torna possível entender a polêmica de Gramsci com as concepções educativas da escola nova. Segundo Soares, Gramsci adota o conceito de atividade em sentido social, como base das relações de hegemonia, mais do que no sentido pedagógico privilegiado pela escola nova, ou pedagogia idealista, que ele considera ancorado na fase 'romântica' desse movimento pedagógico, na qual este se contrapõe à escola jesuítica e à sua pedagogia 'mecânica'. Um dos elementos da concepção escolanovista a que Gramsci dedicará mais atenção será a separação por ela operada entre instrução e educação.

Ele discordará em parte dessa separação, pois, no seu entender, "não é completamente exato que a instrução não seja igualmente educação: a insistência nessa distinção foi um grave erro da pedagogia idealista" (Gramsci, 1979, p. 131), na sua fase 'romântica'. Para Gramsci, essa pedagogia tende a identificar a instrução com a transmissão mecânica de conteúdos escolares, 
e a educação com a formação do aluno, tendo como referência seus interesses e sua vida, marcados ambos por seu estado de desenvolvimento biopsíquico. Nesse sentido, a ênfase na instrução, identificada com a escola tradicional de inspiração jesuíta, poderia até informar a criança, mas não a formaria, pois, reduzindo-a à mera passividade, prejudicaria sua formação. Gramsci considera positiva essa tese, entendida como reação salutar ao enfoque escolástico da educação jesuítica, mas pondera que, exagerando tal posicionamento, em sua 'fase romântica', a pedagogia da escola nova produziu a dicotomia acima referida.

No entender de Gramsci, a dicotomia entre instrução e educação apontada pela pedagogia idealista não resulta da ênfase na instrução, mas na separação, no âmbito da escola, entre esta e a vida social, pois, de acordo com seu ponto de vista, se o 'certo' da cultura evoluída (aquela que a escola aborda) se torna 'verdadeiro' na consciência da criança, é necessário considerar que "a consciência da criança não é algo 'individual' (e muito menos individualizado), mas sim, o reflexo da fração de sociedade civil da qual a criança participa, das relações sociais tais como elas se concentram na família, na vizinhança, na aldeia etc." (Gramsci, 1979, p. 131).

De uma só vez polemiza com dois argumentos da pedagogia que critica: de um lado, aponta o viés individualista que se inscreve na concepção de homem como 'natureza humana em geral' e, de outro, por conta do mesmo viés, para a desconsideração das determinações socioculturais que definem quem é a criança que o professor tem diante de si. O que lhe permite essa crítica é a concepção de homem que deriva do marxismo, isto é, a de que a natureza humana se define pelo "processo de seus atos (...) uma série de relações ativas (...) no qual, se a individualidade tem a máxima importância, não é, todavia, o único elemento a ser considerado" (Gramsci, 1978, p. 38-39). Em suma, "a natureza humana é o conjunto de relações sociais", concepção que considera "a mais satisfatória porque inclui a idéia do devenir: o homem 'devém'", transforma-se continuamente com as transformações das relações sociais" (Gramsci, 1978, p. 43, grifos nossos). Assim, se a criança que o professor tem diante de si é a expressão das relações sociais e se estas relações são marcadas por uma concepção folclórica de mundo, então, como pondera Gramsci, dado o descompasso entre tais relações e os programas escolares, “o 'certo' de uma cultura evoluída” (a que o professor dispõe à criança) se torna "o 'verdadeiro' nos quadros de uma cultura fossilizada e anacrônica" (Gramsci, 1979, p. 131), impedindo a unidade entre instrução e educação.

Todavia, esse não é o destino necessário. De forma coerente com o princípio educativo que investiga e com sua perspectiva política de que a escola pode contribuir para a formação infantil a partir de uma outra perspectiva, articulando organicamente instrução e educação, Gramsci ponderará que, 
na escola, o nexo instrução-educação somente pode ser representado pelo trabalho vivo do professor, na medida em que o mestre é consciente dos contrastes entre o tipo de sociedade e de cultura representado pelos alunos, sendo também consciente de que sua tarefa consiste em acelerar e em disciplinar a formação da criança conforme o tipo superior em luta com o tipo inferior (Gramsci, 1979, p. 131, grifos nossos).

Os grifos objetivam chamar a atenção para aspectos que me parecem centrais nessa formulação, começando pelo último deles, pois é o que remete mais diretamente à sua preocupação política com a atividade educacional: a contribuição que esta possa oferecer, no campo da luta hegemônica, para a constituição de sujeitos sociais com autonomia intelectual-moral, os quais poderão, além de participar, nesta condição, da vida social, atuar no processo de superação da formação social capitalista. A 'aceleração', termo que aparece nos textos de Gramsci em várias oportunidades, refere-se, no meu entender, à sua concepção de que, sendo os homens, devenir, são por isto mesmo construtores da história. Em outros termos, a história futura é mais que o desenrolar 'espontâneo' da vida social. No caso das crianças oriundas de famílias de trabalhadores, essa história depende em muito da articulação entre educação e instrução pelo trabalho vivo do professor. Entendo por essa expressão o compromisso político e social desse professor no sentido de, tomando como ponto de partida a criança que é expressão de relações sociais fossilizadas e anacrônicas, contribuir, na medida das possibilidades de seu trabalho, para a superação dos limites que elas representam para a constituição de sua autonomia intelectual-moral. Todavia, se a escola pode contribuir para a constituição de uma concepção de mundo mais orgânica e de nível superior, há que ponderar também que ela é fruto das mesmas condições que determinam a forma a ser superada, o que depende "do complexo social do qual os homens são expressão" e não "imediatamente dos homens que são professores" (Gramsci, 1979, p. 132).

Cabe, ainda, abordar outro tema, caro a Gramsci, qual seja o da constituição de hábitos de estudo como condição indispensável para a conquista da autonomia intelectual-moral. De sua perspectiva, tal processo exigiria do professor, na escola elementar, o exercício de "moderado dogmatismo" o qual poderia ser "reabsorvido e dissolvido no inteiro ciclo do curso escolar" (Gramsci, 1979, p. 137) - posto que a orientação espontaneísta recomendada pela pedagogia idealista não apenas deixaria de conduzir à aquisição de tais hábitos, mas, para além disto, tornaria inviável o desenvolvimento da instrução de tal forma que se desse efetivamente sua articulação orgânica com a educação. Em outros termos, não contribuiria para a apropriação significativa dos conteúdos concretos ensinados por meio da atividade orientada pelas finalidades da escola unitária. Em consequência, defenderá a posição de que “o estudo é também um trabalho, e um trabalho árduo que exige 
esforço" (Gramsci, 1979, p. 138). É nesse sentido que a escola unitária é escola ativa. Por isso, no embate com a pedagogia idealista, não a criticará de forma total, mas somente os exageros de sua fase romântica, na qual se contrapôs ao mecanicismo do ensino jesuíta. Daí sua recomendação de que caberia identificar os elementos progressistas nela contidos, ou seja, promover a superação da fase romântica por meio da "fase 'clássica', racional, encontrando nos fins a atingir a fonte natural para elaborar os métodos e as formas" (Gramsci, 1979, p. 124).

O que aproxima e distancia Marx e Engels de Gramsci nas suas incursões pelo campo educativo? A meu ver o que os aproxima de modo mais cabal é, de um lado, a perspectiva teórica, ou seja, o materialismo histórico, e, de outro, a preocupação de natureza política que os remete não apenas ao estudo, mas também às ações, que têm por objetivo a superação da formação social capitalista. Nesse sentido, a educação escolar se põe, tanto para Marx e Engels quanto para Gramsci, como possibilidade concreta de elevação cultural e desenvolvimento dos trabalhadores.

Os caminhos seguidos, tendo em vista esse objetivo, foram, no entanto, diferentes. Considero que tais diferenças devem ser tributadas ao fato de que fizeram suas contribuições em momentos históricos diversos. Marx e Engels, no quadro do capitalismo selvagem e no contexto das conturbações políticas e sociais do século XIX, cujas soluções foram buscadas principalmente pelo que Gramsci denominou de "guerra de movimento". Num período histórico em que as crianças da classe operária mal tinham acesso à escola, a possibilidade de poderem trabalhar e receber educação escolar sistemática, propiciada pelas leis fabris, afigurasse-lhes não só como um grande avanço, mas também como alternativa educacional, ou seja, a de combinar educação geral e trabalho de forma mais ou menos direta, na perspectiva aqui examinada.

Gramsci, na segunda e terceira décadas do século XX, defronta-se com outra realidade. Não apenas o processo de industrialização e urbanização havia avançado a passos largos em relação ao período em que Marx e Engels produziam, como também a ciência o havia feito, contribuindo decisivamente para a acumulação capitalista. Como ressaltou Gramsci, as sociedades tinham se tornado mais complexas e as soluções para suas crises tinham de ser buscadas por outras formas que não a "guerra de movimento". Tais constatações, derivadas de sua prática política e das reflexões teóricas, levam-no a conferir grande atenção às disputas ideológicas e às ações no plano da cultura, como dimensão da luta pelo poder, sem afastar, como anteriormente afirmado, a possibilidade da luta armada. As perspectivas desencadeadas pelo desenvolvimento do fordismo, especialmente no que diz respeito à constituição de um novo tipo humano, a clareza da crise da escola nesse contexto e o contato com as experiências educacionais soviéticas e com as proposições 
da escola nova levaram-no a buscar a articulação entre educação geral e trabalho de uma forma muito diversa de Marx e Engels, ainda que com base na mesma raiz teórica, como se procurou mostrar neste texto.

São elaborações que, cada uma a seu tempo, trouxeram contribuições para pensar a educação. Tão importante quanto a especificidade de cada uma é a constatação de que ambas têm outra raiz comum, além das já apresentadas: são proposições que não rejeitam o momento histórico em que são formuladas; antes, dele se alimentam para apontar caminhos educacionais que, embora limitados pelas condições concretas, visam à sua superação e, mais que isto, à superação do modo de produção que as constituiu.

\section{Notas}

1 Professor Titular do Programa de Pós-Graduação em Educação da Universidade de Sorocaba (Uniso), Sorocaba, Brasil. Doutor em Educação: História, Política, Sociedade pela Pontifícia Universidade Católica de São Paulo. <cferretti@fcc.org.br>

Correspondência: Rua das Rosas, 591, Jardim Haras Bela Vista, Vargem Grande Paulista, São Paulo, Brasil, CEP 06730-000.

2 Cabe recordar que, em Gramsci, a categoria 'intelectual orgânico' não se refere tãosomente aos intelectuais forjados pelos setores populares ou que neles não tendo origem abraçam suas causas. Ao contrário, Gramsci propõe que tais setores valham-se do mesmo tipo de ação político-cultural desenvolvido pelas classes dominantes para difundir sua concepção de mundo.

\section{Referências}

FEMIA, Joseph M. Gramsci e o caminho para o socialismo. São Paulo: O Estado de S. Paulo, 25 nov. 1979, p. 150.

GRAMSCI, Antonio. Concepção dialética da história. 3. ed. Rio de Janeiro: Civilização Brasileira, 1978.

Maquiavel, a política e o estado moderno. 3. ed. Rio de Janeiro: Civilização Brasileira, 1978a.
Os intelectuais e a organização da cultura. 3. ed. Rio de Janeiro: Civilização Brasileira, 1979.

MACHADO, Lucilia Regina de Souza. Politecnia, escola unitária e trabalho. São Paulo: Cortez, 1989.

MANACORDA, Mario A. El princípio educativo em Gramsci. Salamanca: Ediciones Siguime, 1977. 
MARX, Karl. O capital: crítica da economia política. Rio de Janeiro: Civilização Brasileira, Livro 1, s/d.

NOGUEIRA, Maria Alice. Educação, saber, produção em Marx e Engels. São Paulo: Cortez, 1990.

NOSELLA, Paulo. O trabalho como princípio educativo em Gramsci. In: SILVA, Tomaz Tadeu (Org.). Trabalho, educação e prática social. Porto Alegre: Artes Médicas, 1991, p. 134-159.

SAVIANI, Dermeval. O trabalho como princípio educativo frente às novas tecnolo- gias. In: FERRETTI, Celso J.; ZIBAS, Dagmar M. L.; MADEIRA, Felícia; FRANCO, Maria Laura P. B. (Orgs.). Novas tecnologias, trabalho e educação: um debate multidisciplinar. 7. ed. Petrópolis: Vozes, 1994, p. 151-166.

Educação: do senso comum à consciência filosófica. São Paulo: Cortez, 1980.

SOARES, Rosemary D. Gramsci, o Estado e a escola. Ijuí: Unijuí, 2000.

VINCENT, Guy; LAHIRE, Bernard; THIN, Daniel. Sobre a história e a teoria da forma escolar. Belo Horizonte: Educação em Revista, n. 33, jun. 2001, p. 7-47. 